\title{
Myopathy with abnormal mitochondria, transient low electron transport capacity in the respiratory chain, and absence of energy transduction at sites 1 and 2 in vitro
}

\author{
U TROCKEL,${ }^{*}$ HR SCHOLTE, $\dagger$ KVTOYKA, * HFM BUSCH, $\dagger$ \\ IEM LUYT-HOUWEN, $\dagger$ JA BERDEN $\ddagger$
}

From the Department of Neurology, University of Düsseldorf, Düsseldorf, FRG, * Departments of Biochemistry I and Neurology, Erasmus University, Rotterdam, $\dagger$ and the BCP Jansen Institute, University of Amsterdam, Amsterdam, The Netherlands $\ddagger$

SUMMARY A male adult with exercise-related myalgia and weakness from the age of 17 years, developed contractions after moderate exertion which were electrically silent. Triglyceride loading or prolonged fasting provoked excessive ketosis. His isolated muscle mitochondria had severe blockade of the respiratory chain, particularly of NADH-CoQ reductase. After 1.5 years a second biopsy was performed. The electron transport capacity of the respiratory chain was much improved, but now a lesion was observed in energy transduction of sites 1 and 2 of the respiratory chain. The unexpected abolishment of respiratory chain blockade was paralleled by only mild clinical improvement.

Metabolic myopathies are now recognised to be caused by a variety of enzymatic disorders which disturb cellular metabolism. Enzyme deficiencies are found in all parts of the cell. Since the discovery of muscular phosphorylase deficiency and of acid maltase deficiency, a cytosolic and a lysosomal defect respectively, a number of other enzymopathies have been detected. ${ }^{1}$ In the last decade the diseased mitochondrion has been found to be the cause of myopathies or of systemic diseases also affecting the muscular system. ${ }^{1-7}$ Many patients have been reported with respiratory chain defects. Those parts of the respiratory chain involved in energy transduction (NADH-CoQ reductase, cytochrome $b c_{1}$, and cytochrome $a a_{3}$ ), are often found to be functionally disturbed. In most patients the transport of reducing equivalents was found to be lowered, while the ATP production, that is proton pumping and ATP synthetase, were not impaired.

Address for reprint requests: Prof KV Toyka, MD, Dept of Neurology, University of Dusseldorf, Moorenstrasse 5, 4000 Dusseldorf 1, Federal Republic of Germany.

Received 8 February 1985 and in revised form 18 July 1985. Accepted 16 October 1985
We describe a patient with transient electron transport defects in the respiratory chain of skeletal muscle mitochondria, who in a second biopsy specimen was found to have a relatively normal electron transport capacity, but a defect in energy transduction at NADH-CoQ reductase and cytochrome $b c_{1}$.

\section{Case report}

This 19-year-old male student was admitted in July 1981 with a chief complaint of muscle aching and weakness related to prolonged exercise. He was well until the age of 17 , when during canoeing he first noticed pain, weakness and muscle cramps in the forearm muscles sufficient to prevent him from going on. He also observed weakness and muscle pain of his thigh muscles on cross country skiing. His previous medical and family history was unremarkable. There was no evidence of exposure to toxic agents or drugs. On examination he was an athletic and healthy man. Blood pressure was $130 / 80 \mathrm{~mm} \mathrm{Hg}$ and pulse rate $76 / \mathrm{min}$. Muscular testing revealed normal strength. At rest muscle bulk and tone were normal. There was no focal wasting or hypertrophy. On repeated fist squeezing of a dynamometer (Martin, Tuttlingen, W Germany) he showed normal maximal force $(12 \mathrm{~N})$, but a $50 \%$ decrease in force was seen after 30 trials when contracture of the forearm muscles occurred. After a few minutes of complete rest, muscle strength returned to its pre-exercise level. There was no evidence of myotonia on percussion. Routine blood tests were normal including CK, SGOT and SGPT and body temperature. On follow up 
examination $1 \frac{1}{2}$ yr later the patient reported a less marked exercise intolerance during work. Mild contractures were still noted on prolonged exercise. Life style, nutrition, or environmental factors had not changed. On formal testing there was only mild weakness (less than $20 \%$ ) on repeated squeezing of the dynamometer with a mild bulking of the forearm muscles.

\section{Methods}

\section{Electromyography}

An EMG study was done in the clinically most affected forearm muscles using needle electrodes connected to a clinical electromyograph (Medelec MS 91).

\section{Metabolic studies}

In all serum samples lactate, pyruvate, $\beta$-hydroxybutyrate and acetoacetate were determined according to standard enzymatic procedures (lactate, pyruvate, $\mathrm{CK}$, and triglycerides by test kits from Boehringer-Mannheim (Mannheim, FRG)). Free fatty acids (FFA) were determined by high pressure liquid chromatography. The ischaemic exercise test was performed in a modification after Munsat. ${ }^{8}$ Blood was drawn from a cubital vein $0,1,2,5,10$, and $15 \mathrm{~min}$ after onset of 30 maximal squeezings of a dynamometer during 60 seconds under forearm muscle ischaemia with the distal cuff remaining above arterial pressure throughout the procedure. The response to long chain triglycerides was studied according to Bertorini et al. ${ }^{9}$ Venous blood samples were taken 0 , 2,4 and $6 \mathrm{~h}$ after ingestion of an oil emulsion containing $1.25 \mathrm{~g}$ of long chain triglycerides $/ \mathrm{kg}$ of body weight. Prior to this test the patient was on a normal diet.

A prolonged exercise test was performed according to Brooke et al. ${ }^{10}$ Blood samples were taken after 15, 30, 45, 60, and $120 \mathrm{~min}$ of cycling on a bicycle ergometer, $15 \mathrm{~min}$ after onset, the work-load was reduced from maximal to half maximal. Exercise was finished after $120 \mathrm{~min}$ and the last blood sample was drawn 180 min after starting exercise.

A fasting test was performed for $38 \mathrm{~h}$. Blood samples were taken after 14, 20, and $38 \mathrm{~h}$. Blood gas was analysed in the second and third blood sample.

Muscle biopsy

Two muscle biopsy specimens were obtained $1 \frac{1}{2}$ yr apart,
Trockel, Scholte, Toyka, Busch, Luyt-Houwen, Berden

from the left and the right biceps. Samples were processed for histochemistry and in vitro mitochondrial studies. Electron microscopy was performed on the second biopsy specimen.

Light and electron microscopy One sample was rapidly frozen and 6-8 $\mu \mathrm{m}$ cryostat sections were processed by routine histological and enzyme histochemical stains according to standard methods. ${ }^{11}$ One sample was fixed in $2.5 \%$ glutaraldehyde phosphate buffer, pH 7.2, embedded in Spurr's medium and cut in semithin and ultrathin sections for standard electronmicroscopy.

\section{Biochemical Methods}

The preparation of homogenates, isolation of mitochondria and the assays of oxidative phosphorylation, beta oxidation, other enzyme activities, carnitine, and protein has been described in Barth et al $^{12}$ and Mooy et al. ${ }^{13}$ The measured P/O ratios were corrected for mitochondrial adenine nucleotides by taking an extra sample just before the addition of ADP. Control values were derived from biopsy samples of patients without evidence of neuromuscular or metabolic disorder.

\section{Results}

\section{Clinical studies}

Electromyography On insertion no myotonic or pseudomyotonic discharge was recorded, nor was $\vec{\Phi}$ there spontaneous activity at rest. On minimal voli- $\frac{?}{\mathbb{Q}}$ tional muscular activity action potentials of normalo duration, amplitude, and shape were seen. The inter ference pattern appeared normal on maximal con- 8 traction. After 10-15 repeated maximal fist closures a응 contraction occurred which was electrically silent. On follow-up examination a similar but much less pro- $?$ nounced contracture could be elicited after 20 maximal contractions with electrical silence on EMG.

\section{Metabolic studies}

The ischaemic exercise test showed a normal rise of blood lactate. Long-chain triglyceride loading and

Table 1 Carnitine, protein, and activities of cytosolic and mitochondrial enzymes in skeletal muscle homogenate

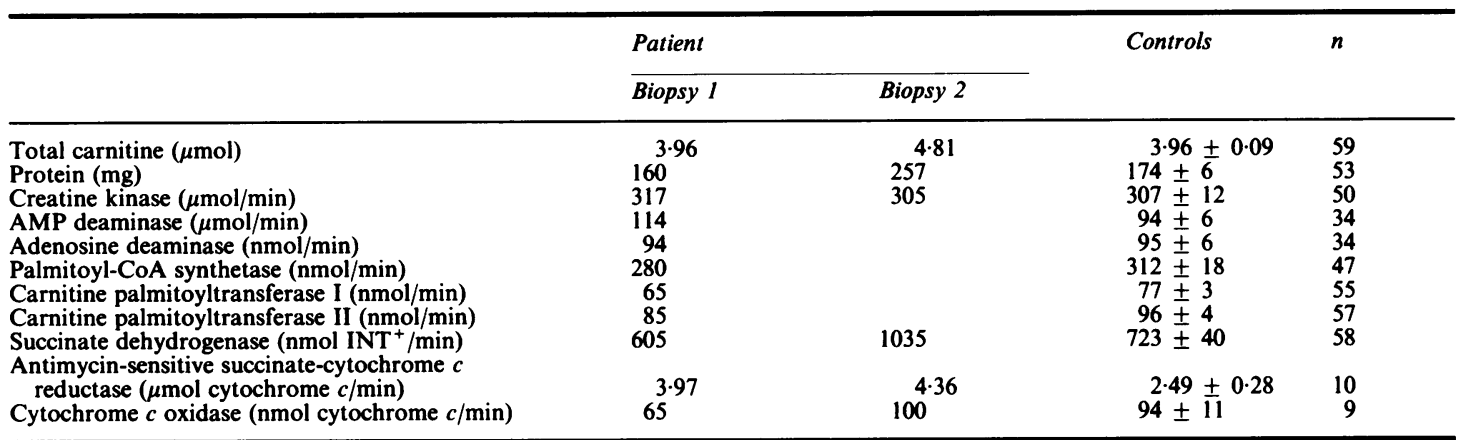

The amount and activities are given per $\mathrm{g}$ wet weight. The average control values are given $\pm \mathrm{SE}$. $\mathrm{n}=$ the number of controls. 
Table 2 Oxygen uptake by muscle mitochondria

\begin{tabular}{|c|c|c|c|c|}
\hline & \multicolumn{2}{|l|}{ Patient } & \multirow[t]{2}{*}{ Controls } & \multirow[t]{2}{*}{$n$} \\
\hline & Biopsy I & Biopsy 2 & & \\
\hline $\begin{array}{l}\text { Pyruvate + malate } \\
\text { Glutamate + malate } \\
\text { Palmitoylcarnitine + malate } \\
\text { Succinate + rotenone } \\
\text { Ascorbate + TMPD }\end{array}$ & $\begin{array}{r}6 \\
26 \\
6 \\
38 \\
109^{a}\end{array}$ & $\begin{array}{c}48 \\
57 \\
33 \\
63 \\
244^{b}\end{array}$ & $\begin{array}{r}84 \pm 6 \\
86 \pm 8 \\
71 \pm 5 \\
111 \pm 9 \\
344 \pm 16\end{array}$ & $\begin{array}{l}17 \\
17 \\
17 \\
17 \\
17\end{array}$ \\
\hline
\end{tabular}

The oxidation rates are in nat oxygen $/ \mathrm{min} / \mathrm{mg}$ protein.

The oxygen uptake was not constant in time. It decreased at $43 \%$ of the initial oxygen concentration.

bThis activity was stimulated by uncoupler to 334 nat oxygen/min/mg.

The stimulation factor of 1.37 is in the control range.

$36 \mathrm{~h}$ fasting caused a much higher level of ketone bodies in the patient than in controls. ${ }^{14} \mathrm{~A}$ test for urinary ketone bodies was positive after $24 \mathrm{~h}$ fasting. After $36 \mathrm{~h}$, blood $\mathrm{pH}$ was $7 \cdot 36$, the base excess $-7 \cdot 3$ and the $\mathrm{pCO}_{2} 30.4 \mathrm{~mm} \mathrm{Hg}$. The prolonged exercise test showed a higher increase of FFA than in controls. The increase of lactate was like in controls. The other data obtained by the tests were normal except for CK after $36 \mathrm{~h}$ of fasting, which increased from 65 to $180 \mathrm{U} / \mathrm{l}$.

\section{Muscle Morphology}

On light microscopy both muscle specimens appeared completely normal. On enzyme histochemistry the fibre type distribution was within the normal limits. Cytochrome-c-oxidase staining was normal. The Gomori trichome stain was not indicative of mitochondrial abnormalities. With oil-red-O and PAS stains no abnormal increase in glycogen or lipid droplets was seen. On electronmicroscopy no changes were noted. The mitochondria were normal in size and shape with regularly arranged cristae (second biopsy).

\section{Biochemical studies in vitro}

Table 1 shows the amount of total carnitine, the activities of cytosolic and mitochondrial enzymes in the two biopsies, which were all in the normal range. Also the electron transport capacity of the cytochrome system as reflected by the activity of antimycinsensitive succinate-cytochrome-c reductase and of cytochrome-c-oxidase were normal. This is in sharp contrast with the polarographic measurement of the respiratory capacity of the isolated mitochondria with the various substrates, which was found to be markedly decreased, especially in the first preparation. The oxidation of pyruvate, glutamate, palmitoylcarnitine, succinate and ascorbate were 7, 30, 8, 34 , and $32 \%$ of the average control rates. Surprisingly, in the second biopsy specimen the velocities were much higher. The respective percentages were now 57, 66, 46, 57, and 71 of control (table 2). The oxidative phosphorylation in the first preparation was

Table 3 Stimulation of oxygen uptake by ADP in muscle mitochondria

\begin{tabular}{|c|c|c|c|c|}
\hline & \multicolumn{2}{|l|}{ Patient } & \multirow[t]{2}{*}{ Controls } & \multirow[t]{2}{*}{$n$} \\
\hline & Biopsy I & Biopsy 2 & & \\
\hline $\begin{array}{l}\text { Pyruvate + malate } \\
\text { Glutamate + malate } \\
\text { Palmitoylcarnitine + malate } \\
\text { Succinate + rotenone } \\
\text { Ascorbate + TMPD }\end{array}$ & $\begin{array}{l}1 \cdot 00 \\
1.43 \\
0 \cdot 50 \\
1 \cdot 12 \\
1 \cdot 31\end{array}$ & $\begin{array}{l}1.83 \\
1.91 \\
1.90 \\
2.06 \\
1.61\end{array}$ & $\begin{array}{l}2.58 \pm 0.20 \\
2.48 \pm 0.16 \\
2.18 \pm 0.19 \\
2.22 \pm 0.13 \\
1.71 \pm 0.08\end{array}$ & $\begin{array}{l}17 \\
17 \\
17 \\
17 \\
17\end{array}$ \\
\hline
\end{tabular}

Table $4 P / O$ ratios in muscle mitochondria

\begin{tabular}{|c|c|c|c|c|c|}
\hline & \multicolumn{2}{|l|}{ Patient } & \multirow[t]{2}{*}{ Controls } & \multirow[t]{2}{*}{$n$} & \multirow[t]{2}{*}{ Theoretical } \\
\hline & $b \times 1$ & $b \times 2$ & & & \\
\hline $\begin{array}{l}\text { Palmitoylcarnitine + malate } \\
\text { Succinate + rotenone } \\
\text { Ascorbate + TMPD }\end{array}$ & $*$ & $\begin{array}{l}0.48 \\
0.65 \\
0.57\end{array}$ & $\begin{array}{l}1.76 \pm 0.42 \\
1.29 \pm 0.27 \\
0.56 \pm 0.11\end{array}$ & $\begin{array}{l}5 \\
5 \\
5\end{array}$ & $\begin{array}{l}2 \cdot 80-2 \cdot 50 \\
2 \cdot 00 \\
1 \cdot 00\end{array}$ \\
\hline
\end{tabular}

The P/O ratios were corrected for glucose-6-phosphate formation before the addition of ADP. The theoretical ratios are calculated on the assumption that one high energy bond is formed per energy transducing site of the respiratory chain. The highest theoretical P/O with palmitoylcarnitine is based upon complete oxidation to $\mathrm{CO}_{2}$, and the lowest upon oxidation to acetylcarnitine.

*The $\mathrm{P} / \mathrm{O}$ ratios in the first preparation were unreliably high since they were not corrected for mitochondrial adenine nucleotides. 
Table 5 Enzyme activities and yield of muscle mitochondria

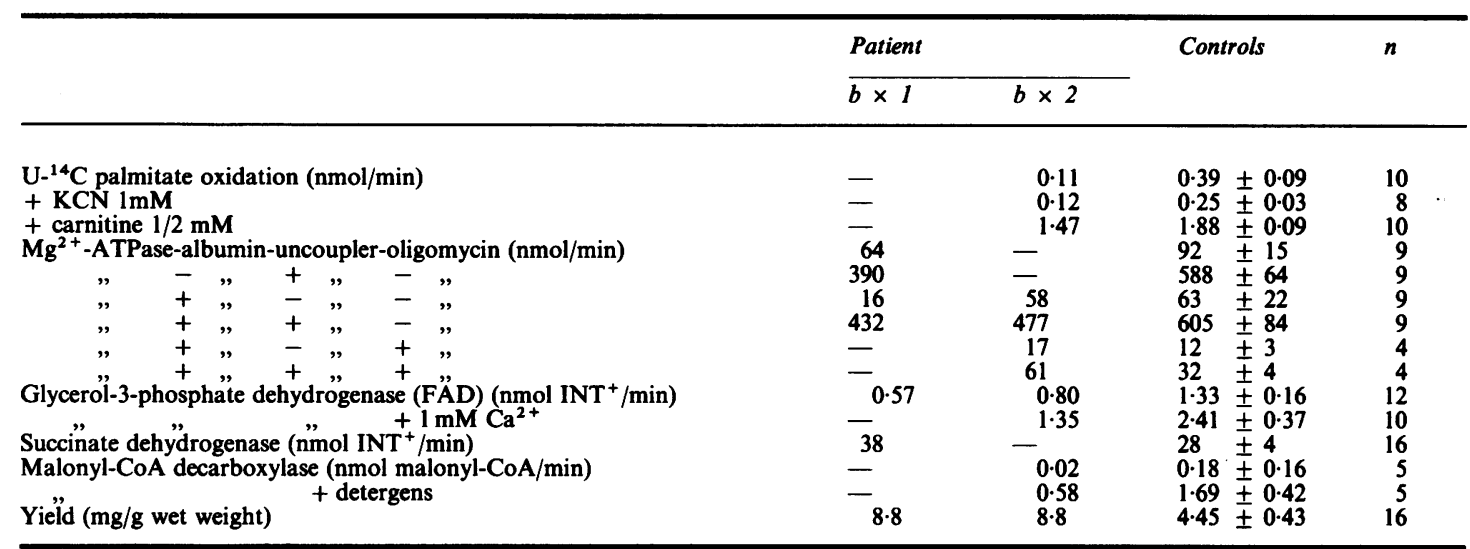

$\mathrm{n}$ denotes number of control values.

more loosely coupled, compared with the second biopsy and to the controls, as reflected by the low stimulation of respiratory rates by ADP. This value decreases in mitochondria from controls and patients when the respiratory rate is below 30 nat oxygen per $\mathrm{min} / \mathrm{mg}$ protein, but in the first preparation, it was also depressed with succinate and ascorbate as substrate (table 3).

Recently we changed our measurement of $\mathrm{P} / \mathrm{O}$ ratio, since we found too high ratios, especially when the oxygen consumption was low. After the correction for mitochondrial adenine nucleotides the $P / O$ ratios were more reliable, and lower than the calculated ratios. In the mitochondria from the second biopsy the $\mathrm{P} / \mathrm{O}$ ratio with ascorbate was found to be identical to the average control value. In contrast to the controls, we found that the $\mathrm{P} / \mathrm{O}$ ratios with succinate, palmitoylcarnitine and ascorbate were the same. This implies that there was no ATP production during electron transport catalysed by NADH-CoQ reductase and $\mathrm{CoQ}$-cytochrome-c-reductase, while electron transport catalysed by cytochrome- $c$-oxidase was accompanied by a normal ATP production (table 4). We found this same abnormality in a girl and her brother (patients of Dr R Rodrigues Pereira, unpublished results). Table 5 shows that the cyanide-

Table 6 The cytochrome content of muscle mitochondria (first biopsy only)

\begin{tabular}{llll}
\hline & Patient & Controls & $n$ \\
\hline Cytochrome $b$ & 0.10 & $0.25 \pm 0.02$ & 5 \\
Cytochrome $c_{1}+c$ & 0.32 & $0.42 \pm 0.04$ & 5 \\
Cytochrome $a a_{3}$ & 0.17 & $0.27 \pm 0.02$ & 5 \\
\hline
\end{tabular}

The cytochrome content is given in $\mathrm{nmol} / \mathrm{mg}$ protein. insensitive palmitate oxidation, residing in the peroxysomes, was lowered in the patient, while the mitochondrial beta-oxidation measured in the presence of carnitine, was normal. This implies normal functioning of the mitochondrial beta-oxidation enzymes and of intramitochondrial coenzyme $A$ and $\mathrm{NAD}^{+}$. The mitochondrial ATP synthetase, measured as $\mathrm{Mg}^{2+}$-ATPase was normally latent, and stimulated by uncoupler. The latent activity was substantially lowered by the addition of albumin, possibly indicating the presence of fatty acid derivates. The bulk of the uncoupler-stimulated activity wase inhibited by oligomycin. The activity of glycerol-3-P? dehydrogenase (FAD) was somewhat decreased compared with the controls, but normally activated by the addition of $\mathrm{Ca}^{2+}$, indicating the absence of calcium overload in the second preparation. The activity of succinate dehydrogenase was normal in the first preparation. In the second preparation the integrity of the mitochondrial inner membrane was measured by the detergent stimulation of malonyl-CoA decarboxylase, a matrix enzyme which is not able to decarboxylate added malonyl-CoA when the inner membrane is intact. Only $3 \%$ of the mitochondria were found to be damaged.

In the first preparation we were able to study the concentration of cytochromes. Cytochrome $b, a a_{3}$, and $c_{1}$ were lowered to 40,63 , and $76 \%$ respectively, on protein basis. The observed decrease in cytochrome $a a_{3}$ agrees very well with the activity of cytochrome-c-oxidase, which was found to be $69 \%$ of control. Since the activity of cytochrome-c-oxidase was normal in the second preparation, it can be concluded that the concentration of cytochrome $a a_{3}$ had returned to normal. 


\section{Discussion}

Problems in mitochondrial energy supply are encountered in an increasing number of patients with myopathies and multisystem diseases. Although the clinical picture varies considerably, muscular weakness and exercise intolerance are striking features. This is also the case in the patient described in this communication.

The metabolic studies revealed an excessive increase of ketone bodies during a $38 \mathrm{~h}$ fasting period, compared with normal controls, ${ }^{14}$ while the exercise study showed a relative increase in FFA levels during exercise. These observations can be explained by a normal fatty acid oxidation in liver, and a decreased consumption of both ketone bodies and fatty acids in muscle. The prominent finding in the mitochondrial preparation from the first biopsy was a reduction in respiratory capacity. Particularly, the oxidation rates with pyruvate and palmitoylcarnitine were very low, which is compatible with a lesion at an early level of the redox system, probably at the NADH-CoQ reductase level. The mitochondrial oxidation of $U_{-1}{ }^{14} \mathrm{C}$ palmitate with carnitine into ${ }^{14} \mathrm{CO}_{2}$ and ${ }^{14} \mathrm{C}$-labelled perchloric acid-soluble intermediates was normal. We have encountered this in a number of other patients with NADH-CoQ reductase deficiency (for example ref 15 ). In the first mitochondrial preparation a decrease was found in cytochrome $b$ and to a lesser extent in cytochrome $a a_{3}$, but this finding cannot explain the very low rate of ascorbate oxidation. A possible explanation for this is that temporarily increased long-chain acyl-CoA in the mitochondrial matrix had inhibited the adenine nucleotide translocator. ${ }^{16-18} \mathrm{An}$ indication of this is the decrease in the stimulation of the oxygen uptake rates by ADP (table 3). The adenine nucleotide translocator inhibitor carboxyatractylate also causes this phenomenon. We think that in the patient's muscle mitochondria the primary defect in NADH oxidation caused an accumulation of long-chain acyl-CoA in the mitochondrial matrix. The patient had a sufficient amount of carnitine to sustain acyl-group transport into the matrix. That the presence of carnitine is essential is suggested by the fact that the oxidation of ascorbate is not much affected in patients with multiple acyl-CoA dehydrogenase deficiency, who were deficient in carnitine. ${ }^{13} 19$

An inhibition of the adenine nucleotide translocator can be verified by uncoupler-stimulation of ascorbate oxidation. Unfortunately this was not tried in the experiments with the first mitochondrial preparation, because we thought at that time that the observed decrease in mitochondrial respiratory capacity was caused by cytochrome-c-oxidase deficiency.
Later this was excluded by measurement of this activity in muscle homogenate (table 1) and of the cytochrome levels in the mitochondrial preparation (table 6).

The second mitochondrial preparation showed an increased capacity of the respiratory chain, although the oxidation rates with the different substrates were lower than the control range. The activities of succinate-cytochrome-c-reductase and of cytochrome-c-oxidase in the homogenate were completely normal (table 1). The adenine nucleotide translocator functioned like in controls, as indicated by the modest uncoupler stimulation of ascorbate oxidation (table 2), and by the normal ADP stimulation of the oxygen uptake rates (table 5).

A completely unexpected finding in the second mitochondrial preparation was not only that the electron transfer capacity of the respiratory chain had increased, but also that the first two energy transducing sites of the respiratory chain were unable to produce ATP. Probably there is a defect in proton pumping by these complexes. Since coenzyme $Q$ is the shuttle between these complexes, there may be an abnormality in this cofactor. This cannot be proven by the present data, since the control strength of coenzyme $Q$ on mitochondrial oxidation is low. ${ }^{20}$ The in vitro absence of proton pumping at site 1 and 2 and the presence of electron transport, implies that the energy must be set free as heat. This apparently did not induce clinical hyperthermia in the patient during exercise possibly owing to intact temperature regulation in vitro.

Biochemical science has greatly advanced our understanding of normal mitochondrial metabolism, but it took lengthy extensive investigations by many expert groups to come at this stage of knowledge. We are only in the beginning of understanding pathological processes in mitochondria. The first reversible defect in cytochrome-c-oxidase has been described in a young child. ${ }^{21}$ In contrast to our adult patient who had ultrastructurally normal mitochondria, in the child's muscle some abnormal mitochondria were seen. The functional and partially reversible defect of our patient lies in the respiratory chain. It is conceivable that in the future more such patients will be discovered. Up to the present most multiple biopsied patients have shown permanent or even progressive mitochondrial defects.

We thank Drs G Stoll and G Schwendemann for performing the electronmicroscopical investigation and Professor M Berger for cooperation, Professor WC Hülsmann for helpful discussion, and the Willem H Kröger Stichting, Rotterdam, for financial support. 


\section{References}

${ }^{1}$ DiMauro S, Metabolic myopathies. In: Vinken PJ, Bruyn GW, eds. Handbook of Clinical Neurology. Amsterdam: North Holland Publishing Co, 1979:Vol 41;175-234.

${ }^{2}$ Carafoli E, Roman I. Mitochondria and disease. Molecular Aspects of Medicine 1980;3:295-429.

${ }^{3}$ Busch HFM, Jennekens FGI, Scholte HR, eds. Mitochondria and Muscular Diseases. Beetsterzwaag, The Netherlands: Mefar BV, 1981.

${ }^{4}$ Scarlato G, Cerri C, eds. Mitochondrial Pathology in Muscle Diseases. Padua: Piccin Medical Books, 1983.

${ }^{5}$ Clark JB, Hayes DJ, Morgan-Hughes JA, Byrne E. Mitochondrial myopathies: disorders of the respiratory chain and oxidative phosphorylation. $J$ Inherit Dis 1984;7 Suppl 1:62-8.

${ }^{6}$ Sengers RCA, Stadhouders AM, Trijbels JMF. Mitochondrial Myopathies, clinical, morphological and biochemical aspects. Eur J Pediatr 1984;141:192-207.

${ }^{7}$ Morgan-Hughes JA, Hayes DJ, Clark JB. Mitochondrial myopathies. In: Serratrice G, et al, eds. Neuromuscular Diseases. New York: Raven Press, 1984:79-87.

${ }^{8}$ Munsat TL. A standardized forearm ischemic exercise test. Neurology (Minneap) 1970;20:1171-8.

${ }^{9}$ Bertorini T, Yeh YY, Trevisan C, Stadlan E, Sabesin S, DiMauro S. Carnitine palmityl transferase deficiency: myoglobinuria and respiratory failure. Neurology (Minneap) 1980;30:263-71.

${ }^{10}$ Brooke MH, Carroll JE, Davis JE, Hadberg JM. The prolonged exercise test. Neurology (Minneap) 1979; 29:636-43.

${ }^{11}$ Dubowitz V, Brooke MH. Muscle Biopsy-A Modern Approach. London: WB Saunders Cy, 1973.

12 Barth PG, Scholte HR, Berden JA, van der Klei-van Moorsel JM, Luyt-Houwen IEM, van $t$ Veer-Korthof ETh, van der Harten JJ, Sobotka-Plojhar MA. An Xlinked mitochondrial disease affecting cardiac muscle, skeletal muscle and neutrophil leucocytes. J Neurol Sci
1983;62:327-55.

${ }^{13}$ Mooy PD, Giesberts MAH, van Gelderen HH, et al. Glutaric aciduria type II: multiple defects in isolated muscle mitochondria and deficient beta oxidation in fibroblasts. J Inherit Dis 1984;7 Suppl 1:101-2.

${ }^{14}$ Haymond MW, Strobel KE, DeVivo DC. Muscle wasting and carbohydrate homeostasis in Duchenne muscular dystrophy. Neurology (Minneap) 1978;28:1224-31.

${ }^{15}$ Scholte HR, Luyt-Houwen IEM, Busch HFM. Fatty acid oxidation in human muscle mitochondria. 2nd Int Symp Monoclonal Antibodies and Inborn Errors of Metabolism. Brugge: Belgian Soc Clin Chem, 1983:115.

${ }^{16}$ Lauquin GJM, Villiers C, Michejda JW, Hrniewiecka LV, Vignais PV. Adenine nucleotide transport in sonic submitochondrial particles: kinetic properties and binding of specific inhibitors. Biochim Biophys Acta 1977; 460:331-45.

${ }^{17}$ Idell-Wenger JA, Grotyohann LW, Neely JR. Coenzyme $A$ and carnitine distribution in normal and ischemic hearts. $J$ Biol Chem 1978;253:4310-8.

${ }^{18}$ Shug AL, Thomsen JD, Folts JD, Bittar N, Klein MI, Koke JR, Huth PJ. Changes in tissue levels of carnitine and other metabolites during myocardial ischemia and anoxia. Arch Biochem Biophys 1978;187:25-33.

${ }^{19}$ Scholte HR, de Visser M, Schutgens RBH, Luyt-Houwen IEM. A riboflavin-responsive patient with glutaric aciduria type II, and her three asymptomatic sisters, all with a defective mitochondrial beta oxidation in muscle and fibroblasts and severe carnitine deficiency. Abstracts op the 3rd Int Symp on Inborn Errors of Metabolism in Humans. Basel: Karger, 1984:40-1.

${ }^{20}$ Tager JM, Wanders RJA, Groen AK, et al. Control o mitochondrial respiration. FEBS Lett 1983;151:1-9.

${ }^{21}$ DiMauro S, Nicholson JF, Hays AP, et al. Benign in fantile mitochondrial myopathy due to reversible cytochrome $c$ oxidase deficiency. Ann Neurol 1983 14:226-34. 